\title{
Evolution of a Development Model for Fruit Industry against Background of an Aging Population: Intensive or Extensive Adjustment?
}

\author{
Bin Yuan, Jintao Zhan and Chao Chen * \\ College of Economics and Management, Nanjing Agricultural University, Nanjing 210095, China; \\ yuanbin678@126.com (B.Y.); jintao.zhan@njau.edu.cn (J.Z.) \\ * Correspondence: cchen@njau.edu.cn; Tel.: +86-25-8439-6687
}

Received: 5 December 2017; Accepted: 24 December 2017; Published: 26 December 2017

\begin{abstract}
As an important starting point for optimizing the structure of agricultural products and implementing green production methods, the direction of orchard management development is directly related to the success of "supply side" reform in the fruit industry in China. However, in the context of the progressive aging of the rural labor force, is the old labor force still capable of the high labor intensity and fine cultivation management needed, such as for pruning, or to maintain or improve the application efficiency of fertilizers? In this paper, based on the micro-production data of peach farmers in Jiangsu Province, we explore the influence of aging on the management of fruit trees and further introduce fruit tree management into the production function to analyze the effects of different orchard management methods on fertilizer efficiency. The results show that with the increase of labor force age, although the total labor investment of aged farmer households has somewhat increased, significant differences exist in the distribution of labor investment between the different production processes due to the different labor demands from the various production processes. In technical stages that demand good physical capabilities, such as pruning and flower/fruit thinning, elderly farmers have significantly reduced labor investment than younger ones, and this relative shortfall further reduces the marginal output of their chemical and organic fertilizers. Foreseeably, the aging of the rural labor force will have a negative impact on the efficiency of chemical and other fertilizers, cost-cutting, and profit-making in the fruit and nut industries, which have the same management methods for pruning and flower (fruit) thinning. Therefore, this paper offers relevant policy recommendations for the optimization of production tools, expansion of operation scale, and development of socialized services for the fruit industry, etc.
\end{abstract}

Keywords: aging; management mode; economic sustainability; ecological sustainability

\section{Introduction}

As a backbone industry that alleviates poverty in vast rural areas and creates wealth for farmers, China's fruit industry has long maintained a rapid growth trend. In 2014, China's total fruit output had reached 261.422 million tons, with a cultivation area of 13,127.2 thousand hectares, aspects that have ranked China as the first in the world for many years. The fruit industry has become China's third largest agricultural cultivation industry after food crops and vegetables. However, while the industry enjoys rapid development, it is facing increasing internal and external pressures. On the one hand, China's fruit imports continue to rise. The China Rural Statistical Yearbook shows that fruit imports reached 3.84 million tons in 2014, an increase of $270.29 \%$ compared with 1.21 million tons in 2002 . Fruit imports have maintained growth for 12 consecutive years, and the growth rate is accelerating significantly. The strange phenomenon of "high production and high import" is apparent. However, fertilizer application in the fruit cultivation process has also increased sharply. In 2014, the total amount 
of fertilizer applied in fruit cultivation in the country had reached 543.5 million tons, far higher than the 398.1 million tons used on crops and the 203.4 million tons used on corn, and it is still maintaining a rapid growth rate. Therefore, how to further optimize the structure of fruit products, promote a transition to green production modes, and further improve the efficiency of chemical fertilizers to achieve zero growth in fertilizer usage are significant for enhancing the capacity for the sustainable development of agriculture and achieving "supply side" reform of the fruit industry.

Unlike traditional field crops, the development of fruit trees in different growth periods is often unbalanced under natural conditions. If fruit trees grow too fast, they are more likely to fruit only in alternate years or to fruit excessively, which can greatly reduce the commercial value and profits of fruit tree cultivation [1]. Therefore, in managing fruit trees, usually artificial pruning, thinning of flowers (fruits), and other fine management techniques are applied to balance the relation between vegetative growth and reproductive growth, thus contributing to the absorption of fertilizers and the maintenance of fruit quality and production stability [2]. However, due to the lack of depth of integration between agricultural machinery and agronomy in China, fine management techniques, such as the pruning and thinning of flowers and fruits, are mainly achieved by manual sawing and cutting by laborers who must also climb ladders and hills. These efforts require intensive labor and have certain safety risks [3]. Therefore, from the mode and characteristic of technology usage, the pruning and thinning of flowers (fruits) and other fine management techniques clearly have labor-intensive properties, and the degree of investment depends almost entirely on the amount and quality of labor investments [4].

At the same time, China's rural labor force structure is rapidly changing. According to the results of the sixth census, the population aged 60 and above accounts for $13.26 \%$ of the total population, and the portion aged 65 and above accounts for $8.87 \%$. In the rural population, among long-term residents aged 16 and above, the proportion of those aged 60 and above has reached $22.98 \%$ [5-8]. Existing studies have almost unanimously agreed that China will face serious laborer-aging problems in the future. In addition, given the differences in the rate of agricultural participation among the different genders, age groups, and health conditions, a significant decline will occur in the number of workers that are truly engaged in agricultural production. Therefore, the changes and trends in the agricultural labor force will have a profound impact on rural development and agricultural production. Some scholars have argued that the aging of the labor force caused a shift to extensive and monoculture farming, and the long-term impact will adversely affect agricultural output and endanger the nation's food security; thus, the changes in rural labor, especially in the case of an aging labor force, will have a negative impact on China's agricultural production [9]. With the decline of physical strength, innovation ability, and cognitive level, elderly farmers have significantly lower production efficiency than young and middle-aged farmers (their marginal output values for the main production elements, such as chemical fertilizers and pesticides, as well as their investments in land, capital, and machinery are all lower than for younger farmers); thus, the aging of the agricultural labor force will seriously restrict the development of China's agriculture $[10,11]$. At the same time, some scholars believe that, compared with the young and middle-aged labor force, the elderly labor force does not show significant difference in the investment in production elements, decision-making on cultivated area, land-use efficiency, and yield per unit area; thus, the aging of the rural labor force will not have a negative impact on agricultural production [12-14]. In contrast, with an increase in the level of agricultural mechanization, young and middle-aged migrant workers greatly promoted the demand for agricultural production machinery.

The focus of existing research is mainly on the analysis of the impact of the aging labor force on food production but ignores the impact on fruit production, which is more labor-intensive. In recent years, with the continued increase in the application of chemical and organic fertilizers in fruit cultivation, farmers should invest more labor force in the pruning and thinning of flowers (fruits) to guarantee effective usage of fertilizers. Therefore, from a management point of view, in the context of the aging labor force, will the decline in physical strength of elderly farmers affect the level of investment in pruning and thinning of the flowers (fruits), and will it thus lead to a lack of economy in 
chemical and organic fertilizers? To answer these questions, this study considers the peach farmers in Jiangsu Province as an example and analyzes the effect of the aging labor force on the efficiency of fertilizer application by studying the pruning and thinning of flowers and fruits. Notably, during the process of fruit cultivation, farmers will use a certain percentage of organic fertilizer in addition to chemical fertilizers; therefore, this study will also consider the impact of the aging labor force on organic fertilizer efficiency.

\section{Theoretical Framework}

Under the existing technical conditions, fine management techniques that center on pruning and thinning of the flowers and fruits are still unable to realize an effective substitution of machinery for the human labor force. Therefore, with the increase in labor force age and the decrease in physical strength, an elderly labor force must work more to accomplish the same task. As economically rational persons, farmers will make decisions that match their individual expectations and objectives based on their production goals and family circumstances. Compared with younger farmers, when making decisions, elderly farmers not only take profit maximization as the goal but also consider personal leisure and other family factors, such as caring for grandchildren, and for the different age groups, significant differences exist in the effects of leisure and other family activities. Therefore, using the standard farmer model as the basis, this study further introduces the age variable $t$ and constructs a dynamic effect model to explore the impact of aging on the degree of investment in technical aspects, such as the pruning and thinning of flowers and fruits, to reflect the impact of the aging labor force on the management methods of fruit orchards. The specific model is as follows:

$$
\begin{array}{cc}
\text { Max } & U=\left(W, f\left(l_{1}\right)\right) \\
\text { s.t } & W=Y_{0}+Y\left(D_{i}\right) \\
& D_{i}=g(t) \times l_{2} \\
& T=l_{1}+l_{2}
\end{array}
$$

In the above, $U$ is the total utility of the farmers, which is a function of the production income $W$ and the leisure time $l_{1}$. Because of the difference in utility in different leisure time periods, this study basically constructs the utility function of leisure time $f\left(l_{1}\right)$. With the increase in age, the utility of the unit leisure time on farmers gradually increases; that is, $f^{\prime}\left(l_{1}\right)>0, f^{\prime \prime}\left(l_{1}\right)>0 . Y_{0}$ is the production income without any investment in the pruning or thinning of flowers or fruits; $Y\left(D_{i}\right)$ is the increase in profit due the quantity of technical investment $D_{i}$, such as in standard pruning; and $i$ represents the pruning and thinning of flowers (fruits). Based on the actual situation of fruit-tree cultivation, the degree of technical investment in the pruning and thinning of flowers (fruits) depends on the amount of labor invested by the farmer in the above two key processes. Therefore, this study represents the degree of investment through the amount of labor that farmers invest in the key technical aspects of pruning and thinning of flowers (fruits). As aging causes a decline in labor force and technology use, a difference exists between the actual investment (labor) $l_{2}$ and the standard investment $D_{i}$; hence, we introduce the function $\mathrm{g}(\mathrm{t})$ to represent the adjustment coefficient between the actual investment $l_{2}$ and the standard investment $D_{i}$ for a farmer aged $t$, taking values from the range of $(0,1)$. With an increase in age, the adjustment coefficient between the actual investment $l_{2}$ and the standard investment $D_{i}$ decreases; that is, $g^{\prime}(t)<0$. T is the total time that farmers can use. Notably, as important cultivation and management techniques for fruit trees, an investment in the pruning and thinning of the flowers (fruits) is only effective on the premises of investment in fertilizers, pesticides, etc. Only when the basic investments of fertilizers and pesticides are in place would follow-up investment in management technology have value and meaning. Therefore, this study will view pre-production labor investment as a fixed value and only discuss the decision-making relation between technical investment and leisure time. 
According to (1), the Lagrangian function is constructed as follows:

$$
\phi=U\left(W, f\left(l_{1}\right)\right)+\lambda\left[Y_{0}+Y\left(D_{i}\right)-W\right]+\beta\left(l_{1}+l_{2}-T\right)
$$

$W, l_{1}, l_{2}, T$, and $t$ are further derived as follows:

$$
\begin{gathered}
\partial U / \partial l_{1}=-\beta / \lambda \\
\partial \mathrm{U} / \partial l_{1}=-\beta-\lambda \cdot\left(\partial \mathrm{Y} / \partial D_{i}\right) \cdot g(t) \\
\partial U / \partial t=-\lambda \cdot\left(\partial Y / \partial D_{i}\right) \cdot(\partial g / \partial t) \cdot g(t)
\end{gathered}
$$

Based on Formula (4) and (5):

$$
\frac{\partial l_{2}}{\partial t}=\frac{\frac{\partial Y}{\partial D_{i}} \cdot \frac{\partial g}{\partial t} \cdot l_{2}}{\frac{\partial Y}{\partial D_{i}} \cdot g(t)-\frac{\partial W}{\partial l_{1}}} ; \frac{\partial t}{\partial l_{2}}=\frac{g(t)}{\frac{\partial g}{\partial t} \cdot l_{2}}-\frac{\partial W}{\partial Y} \cdot \frac{\partial D_{i}}{\partial l_{1}} \cdot \frac{1}{\frac{\partial g}{\partial t} \cdot l_{2}}
$$

According to the above range of values (non-negative) of $g(t)$ :

$$
D_{i}=g(t) \cdot l_{2}=g(t) \cdot\left(T-l_{1}\right) \partial D_{i} / \partial l_{1}=-g(t)<0
$$

Often, as age increases, the elderly labor force will experience a decline in physical capabilities, and the relation between physicality and age is not a simple linear relation. That is, the rate of physical decline is usually much higher than that of aging; therefore, we can derive that $\partial g / \partial t<0$ and then further deduce the following:

$$
\partial t / \partial l_{2}<0 ; \partial l_{2} / \partial t<0
$$

Therefore, with the increase in the degree of aging of the labor force, farmers will reduce investments in pruning and flower/fruit thinning. According to Formula (6), we know that when farmers have a fixed amount of free time, the impact of the aging labor force on the farmers' investments in pruning, etc. depends on the marginal value of the technical investment, the marginal effect of leisure on the farmers, and the loss of unit labor investment caused by aging and other factors.

\section{Model Description and Solution}

\subsection{The Impact of Aging Labor on Technological Investment}

According to the framework of the above analysis, this study analyzes the impact of an aging labor force on peach production by examining cross-section data and thus does not consider the individual effect and time effect of the model. The empirical model of the impact of aging labor on labor investment in different phases of production thus can be set as follows:

$$
H_{i, j}=\alpha+\beta \text { Young }_{i}+\mu \text { Old }_{i}+\theta M_{i}+\kappa Z+\gamma P+\varepsilon_{i}
$$

$H_{i, j}$ represents the management mode of the $i$-th farmer, expressed by the degree of investment of the farmer in the pruning and thinning of flowers (fruits). The independent variables of the model include the following four parts. The first independent variable is the key explanatory variable of this study, i.e., the degree of aging of the agricultural labor force. In the model, the labor force is further divided into three groups: 40 years old and below, 41-60 years old, and 61 years old and above, with the 41- to 60-year-old group considered as the benchmark. Two dummy variables of young and old are constructed to express the under- 40 group and the above- 61 group. Among them, the under- 40 group (young $=1$ ) mainly represents inexperienced farmers who just started in peach cultivation and production, and the above-61 group (old =1), the aging and physically declining elderly farmers. $M_{i}$ is the control variable. According to previous research, factors influencing the investment of production 
elements can be divided into three categories. First, a variable of individual and family characteristics to account for the heterogeneity of the farmers, $M_{1}$ represents the number of people in the labor force, expressed by the number of people over eighteen years in a family. $M_{2}$ represents the number of years engaged in peach cultivation from beginning to the present. $M_{3}$ represents whether they participated in cooperatives rendering services for saleing and technical training. $M_{4}$ represents the number of technical training sessions attended. The second variable of $Z$ is land situation-that is, the amount of land, which is used to control for the impact of land characteristics on farmers' production decisions. The third variable of $P$ is the price of labor expressed by daily wages, which is used to control for the cost of labor on the farmer labor investment.

Due to the differences in operation models and business concepts, large differences could exist in labor investment in the same processes, especially in technical ones. For example, those committed to fine management usually choose to invest more labor force in technical stages, such as in pruning and bagging, to improve the quality of the fruit output. Farmers opting for extensive management may put in relatively low effort in the technical stages, which leads to extreme values of labor force investment among the different types of farmers. Most of the previous regression models use mean regression, which analyzes the explanatory variables and explained variables, which are extremely susceptible to extreme values. Therefore, in this study, we selected the quantile regression model proposed by Koenker and Bassett (1978) to analyze the distribution of labor in the different processes [15].

\subsection{Estimation of Marginal Output under Different Degrees of Technical Investment}

In view of the potential impact of pruning and flower thinning on the marginal output of chemical fertilizers in the cultivation of peach and other fruit trees, if the traditional C-D (short for Cobb-Douglas) function or transcendental logarithm function is used to estimate the marginal output [16-18], it is likely to overestimate the actual marginal output and underestimate the marginal output of the labor force. Therefore, to capture the impact of this technical investment on the marginal output of chemical fertilizers and other factors and then to acquire the real marginal output of the key element, this study adds a variable for the degree of technical investment in the pruning and thinning on top of the traditional C-D function and also recognizes the need to add into the model the product of this variable and the natural logarithm of the variables of chemical fertilizers and organic fertilizers [19]. The final model equation is as follows:

$$
\ln Y_{i}=\beta_{0}+\beta_{1} \ln H_{i, j}+\beta_{2} \ln N+\beta_{3} \ln O+\beta_{4}\left(\ln F_{1} \times \ln H_{i, j}\right)+\beta_{5}\left(\ln F_{2} \times \ln H_{i, j}\right)+\beta_{6}\left(\ln L \times \ln H_{i, j}\right)
$$

$Y$ is the total output of peaches. To avoid potential regional differences in production, this paper represents output by the farmer's total output value. $H_{i, j}$ is the management mode, as defined in the previous section. $N$ is the total pesticide applied, expressed by the cost of pesticide purchase. $F_{1}$ is the amount of chemical fertilizer used, expressed by the purchase cost of fertilizers. $F_{2}$ is the organic fertilizer used, expressed by the purchase cost of organic fertilizers derived from human excreta, animal excreta and manure, etc. $L$ is the labor input in peach cultivation, expressed through the sum of the farmers' own labor forces and the number of workers hired. $O$ is the other costs incurred during cultivation, including mechanical costs, maintenance costs, etc. Three interactive items of $\ln F_{1} \times \ln H_{i, j}$, $\ln F_{2} \times \ln H_{i, j}$, and $\ln L \times \ln H_{i, j}$ are used to control for the effect of management mode. Therefore, the marginal output of chemical fertilizers, organic fertilizers, and labor can be expressed as:

$$
\partial Y_{i, \mathrm{~b}} / \partial F_{1}=\beta_{4} \ln H_{i, j} ; \partial Y_{i, \mathrm{~b}} / \partial F_{2}=\beta_{5} \ln H_{i, j} ; \partial Y_{i, \mathrm{~b}} / \partial L_{i}=\beta_{6} \ln H_{i, j}
$$

\subsection{Analysis of Endogenous Problems}

As technical investments such as pruning and flower/fruit thinning are mainly dependent on the input of the labor force, the heterogeneity of the different labor force participants in terms of skills etc. likely lead to differences in the potential degree of investment of farmers in these technical processes. 
Therefore, if we treat the total labor deployed in technical processes as the dependent variable, and analyze the impact of different management methods on chemical fertilizers application, endogenous problems may arise with the model. Therefore, based on the study of Wang Jing (2012) and others [20], this study tries to avoid the endogenous problems caused by the heterogeneity of the labor force by constructing the proportion of the labor force involved in the technical process to total labor investment in order to measure the distribution of famers' labor force deployment. The specific indicators are set as follows:

$$
H_{i, j}=L_{i, j} / \sum_{j=1}^{7} L_{i, j}
$$

According to the previous analysis, this study will divide the cultivation process into basic production and technical management. The basic production process includes land preparation, fertilizer application, pesticide application, bagging, and picking. The technical management processes include pruning and flower/fruit thinning. $j$ represents the five key production processes of pruning, flower thinning, bagging, fertilizer application, and pesticide application. $H_{i, j}$ indicates the amount of labor invested in the process. Relatively speaking, the higher the $H_{i, j}$ value for pruning and thinning, the higher the degree of investment in these two technical processes.

\section{Data Source and Description Analysis}

As a developed province in eastern China, Jiangsu Province has maintained a rapid transfer rate of the agricultural labor force for a long time, and thus, the aging trend in its agricultural labor force is more prominent [21]. As a main producer of peaches in southern China, the province reached a cultivated area of 44.15 thousand hectares in 2014. The peach tree has become the type of fruit tree with the largest cultivar area in Jiangsu. Therefore, choosing Jiangsu Province as a sample area for the study can reflect to a certain extent the impact of aging on the labor force involved in peach and other fruit production. According to the peach production, acreage, and farmer household income levels of the different main producing areas in 2015, we picked three prefecture-level cities, namely Xuzhou, Changzhou, and Wuxi, plus six townships (towns) and 18 villages as our sampling region, by using system sampling and K-means Cluster. The contents of the questionnaire include basic demographic data for the individuals and families, cultivation area of the peach trees, investment of the key elements, use of technology, and sales. After removal of the invalid samples, a total of 256 valid questionnaires were obtained.

The business operations data of the 256 farming households are shown in Table 1. Due to the constraint of element substitution, as the farming labor force ages, the amount of labor required per acre shows an increasing trend, whereas the number of employees is declining. In other words, in the face of aging-caused physical decline, older farmers respond by increasing their own labor rather than hiring more workers to make up for it. At the same time, the level of investment in fertilizers and pesticides in the elderly group, especially among the 61- to 70-year-old farmers, is significantly higher than that of the younger farmers. Based on the above analysis, from the perspective of crop production characteristics, the increase in fertilizer investment is bound to require farmers to increase investment in pruning and thinning flowers and other technical aspects to ensure the output efficiency. However, the amount of labor invested in technical processes, such as pruning, flower thinning, and bagging in the elderly group is significantly lower than that of the younger group and shows a declining trend as age advances. Although the changes in labor investment in various processes in production as the age of sampled farmers change to a certain extent confirmed the analysis framework of this paper, notably, for technical investments, with the increase in labor force age, the level of labor skills may also gradually rise, thereby reducing the unit workload of labor investments. Therefore, whether the aging labor force will lead to a different allocation of labor in the different production processes and thus affect the application efficiency of fertilizers and other key factors needs further measurement and analysis. 
Table 1. Description and analysis of the operation status of farmers.

\begin{tabular}{ccccccc}
\hline Investment in Key Elements & $\begin{array}{c}\mathbf{3 0 - 4 0} \\
\text { Years Old }\end{array}$ & $\begin{array}{c}\mathbf{4 1 - 5 0} \\
\text { Years Old }\end{array}$ & $\begin{array}{c}\mathbf{5 1 - 6 0} \\
\text { Years Old }\end{array}$ & $\begin{array}{c}\mathbf{6 1 - 7 0} \\
\text { Years Old }\end{array}$ & $\begin{array}{c}\text { Above 70 } \\
\text { Years Old }\end{array}$ & Mean \\
\hline Sample size & 25 & 48 & 72 & 90 & 21 & 256 \\
Total labor force (worker/mu) & 26.136 & 29.347 & 31.719 & 35.270 & 31.059 & 33.769 \\
Total hired worker (worker/mu) & 3.029 & 7.152 & 1.904 & 0.819 & 0.744 & 2.725 \\
Chemical fertilizer investment (yuan/mu) & 584.036 & 415.543 & 548.494 & 501.450 & 480.508 & 495.586 \\
Organic fertilizer investment (yuan/mu) & 398.705 & 420.023 & 788.088 & 800.920 & 773.554 & 757.018 \\
Pesticides investment (yuan/mu) & 235.187 & 321.273 & 537.429 & 439.270 & 515.663 & 436.026 \\
Percentage of fertilizer to worker (\%) & 0.151 & 0.147 & 0.154 & 0.153 & 0.227 & 0.178 \\
Percentage of pesticides to worker (\%) & 0.175 & 0.179 & 0.190 & 0.224 & 0.202 & 0.182 \\
Pruning worker percentage (\%) & $28.212 \%$ & $24.412 \%$ & $22.021 \%$ & $15.624 \%$ & $14.761 \%$ & $20.165 \%$ \\
Flower thinning worker percentage (\%) & $12.048 \%$ & $17.901 \%$ & $18.940 \%$ & $14.213 \%$ & $14.055 \%$ & $16.578 \%$ \\
\hline
\end{tabular}

Note: Fertilizer investment includes chemical and organic fertilizers.

\section{Results}

\subsection{Estimation of the Impact of an Aging Labor Force on Farmers' Technical Investments}

Based on the above analysis, this study further selects $0.25,0.5$, and 0.75 to estimate the effect of labor age on the investment in pruning and flower/fruit thinning. The estimation results of the specific model are shown in Table 2. The results show that in the pruning investment model, the investment from young farmers is obviously higher than that of the benchmark group. With an increase in the proportion of workers involved in pruning, i.e., for farmers who place a greater emphasis on pruning, the difference between them and the benchmark group is even bigger. In contrast, the variables of the older group, although not significant in all cases, were significant at the 0.25 and 0.5 quantile levels, so we can still consider that in most cases, the elderly labor force invests significantly less in pruning than the benchmark group. Unlike young farmers, as the investment in pruning drops, the difference between the elderly farmers and the benchmark group gradually increases. That is, for farmers with relatively lowered degrees of investment in pruning, as the labor age increases, they will significantly reduce their labor investment in pruning.

Table 2. Estimated results of the impact of labor age on different technical investments.

\begin{tabular}{|c|c|c|c|c|c|c|}
\hline \multirow{2}{*}{ Variable } & \multicolumn{3}{|c|}{ Proportion of Labor Involved in Pruning } & \multicolumn{3}{|c|}{ Proportion of Labor Involved in Flower/Fruit Thinning } \\
\hline & 0.25 & 0.50 & 0.75 & 0.25 & 0.50 & 0.75 \\
\hline Young & $\begin{array}{c}0.0415 * \\
(1.85)\end{array}$ & $\begin{array}{c}0.0688^{* * *} \\
(2.70)\end{array}$ & $\begin{array}{l}0.103 * \\
(1.91)\end{array}$ & $\begin{array}{l}-0.0288 \\
(-1.15)\end{array}$ & $\begin{array}{l}-0.0129 \\
(-0.34)\end{array}$ & $\begin{array}{c}0.0228 \\
(0.52)\end{array}$ \\
\hline Old & $\begin{array}{c}-0.0531^{* * *} \\
(-3.57)\end{array}$ & $\begin{array}{c}-0.0336^{*} \\
(-1.72)\end{array}$ & $\begin{array}{l}-0.0087 \\
(-0.17) \\
\end{array}$ & $\begin{array}{c}-0.0407^{*} \\
(-1.82)\end{array}$ & $\begin{array}{c}-0.0495^{* *} \\
(-2.24)\end{array}$ & $\begin{array}{c}-0.0686^{* * *} \\
(-2.63)\end{array}$ \\
\hline Labor & $\begin{array}{l}-0.0104 \\
(-0.85) \\
\end{array}$ & $\begin{array}{l}0.0007 \\
(0.05)\end{array}$ & $\begin{array}{l}0.0134 \\
(0.42)\end{array}$ & $\begin{array}{l}-0.0141 \\
(-0.99) \\
\end{array}$ & $\begin{array}{c}-0.0353 * \\
(-1.94)\end{array}$ & $\begin{array}{l}0.0191 \\
(0.76)\end{array}$ \\
\hline Time & $\begin{array}{l}0.0016 \\
(1.49)\end{array}$ & $\begin{array}{c}0.0030^{* * *} \\
(2.60)\end{array}$ & $\begin{array}{c}0.0058^{* * *} \\
(2.87)\end{array}$ & $\begin{array}{l}0.0004 \\
(0.40)\end{array}$ & $\begin{array}{l}-0.0002 \\
(-0.19) \\
\end{array}$ & $\begin{array}{l}0.0003 \\
(0.20)\end{array}$ \\
\hline Patter & $\begin{array}{l}-0.0241 \\
(-1.13)\end{array}$ & $\begin{array}{c}0.0092 \\
(0.40)\end{array}$ & $\begin{array}{l}-0.0069 \\
(-0.22)\end{array}$ & $\begin{array}{c}-0.0459^{* *} \\
(-2.53)\end{array}$ & $\begin{array}{l}-0.0253 \\
(-1.04)\end{array}$ & $\begin{array}{c}-0.0507^{*} \\
(-1.90)\end{array}$ \\
\hline Tech & $\begin{array}{l}-0.0059 \\
(-0.67)\end{array}$ & $\begin{array}{l}-0.0076 \\
(-1.17) \\
\end{array}$ & $\begin{array}{c}-0.0162 * \\
(-1.92)\end{array}$ & $\begin{array}{l}-0.0046 \\
(-0.92) \\
\end{array}$ & $\begin{array}{l}-0.0017 \\
(-0.22)\end{array}$ & $\begin{array}{l}-0.0156 \\
(-1.36) \\
\end{array}$ \\
\hline Size & $\begin{array}{l}0.0006 \\
(1.54)\end{array}$ & $\begin{array}{l}0.0003 \\
(0.90)\end{array}$ & $\begin{array}{l}0.0003 \\
(0.50)\end{array}$ & $\begin{array}{l}0.0005 \\
(1.39)\end{array}$ & $\begin{array}{l}-0.0001 \\
(-0.17) \\
\end{array}$ & $\begin{array}{l}-0.0001 \\
(-0.26) \\
\end{array}$ \\
\hline Price & $\begin{array}{c}-0.0047^{* * *} \\
(-3.10)\end{array}$ & $\begin{array}{c}-0.0067^{* * *} \\
(-4.22)\end{array}$ & $\begin{array}{c}-0.0087^{* * *} \\
(-2.74)\end{array}$ & $\begin{array}{l}0.0036 \\
(1.34)\end{array}$ & $\begin{array}{c}0.0047^{* *} \\
(2.03)\end{array}$ & $\begin{array}{l}0.0042 \\
(1.35)\end{array}$ \\
\hline _cons & $\begin{array}{c}0.1577^{* * *} \\
(5.91)\end{array}$ & $\begin{array}{c}0.1584^{* * * *} \\
(4.77)\end{array}$ & $\begin{array}{c}0.1998^{* *} \\
(2.20)\end{array}$ & $\begin{array}{c}0.1089^{*} \\
(1.83)\end{array}$ & $\begin{array}{c}0.2167^{* * *} \\
(3.70)\end{array}$ & $\begin{array}{c}0.2245^{* * *} \\
(3.55)\end{array}$ \\
\hline$R^{2}$ & 0.2325 & 0.2012 & 0.3125 & 0.3210 & 0.2651 & 0.2363 \\
\hline Obs & & 256 & & & 256 & \\
\hline
\end{tabular}


The estimated results of the flower/fruit investment model show no significant difference between young farmers and the benchmark group but do show significant difference between the elderly farmers and the benchmark group, with the former investing significantly less in the flower/fruit thinning. Unlike with pruning, when the proportion of investment in the flower/fruit thinning increases, the difference between the elderly farmers and the benchmark group gradually increases. The above empirical results verified to a certain extent the hypothesis of this study; that is, with advancing age, the elderly labor force is no longer able to meet the highly intensive technical demands of pruning and flower thinning, and their investment in the above is significantly lower than for younger farmers.

\subsection{Estimation of the Effect of Different Technical Investments on Fertilizer Application Efficiency}

In addition to estimating the marginal output of the chemical and organic fertilizers using the amended C-D function that considers the degree of investment in technical processes, this study also uses the traditional C-D function to estimate and compare that. The Prob > chi2 of Hausman specification test result was 0.0426 , which showed that endogeneity did exist in the model. The specific model estimates are shown in Table 3. From the results of the model significance test, the F values of the traditional C-D production function model, the production function model with the pruning process included, and the production model with flower thinning process included are 32.34, 50.98, and 40.85 , respectively, and the corresponding significance levels of the models are all 0.00 . In other words, all three models passed the significance test.

From the estimation results of the model and based on the traditional C-D production function model, the marginal outputs of both chemical and organic fertilizers are estimated to be greater than zero, while the amount of labor investment is less than zero. All three passed the significance test; that is, they have shown to a certain extent that the sampled farmers did not invest excessively in chemical or organic fertilizers. On the other hand, the amended production function, while accounting for the degree of investment in technical aspects, gave conflicting estimated results. In the production function models with the degree of investment in pruning and flower/fruit thinning considered, the interaction coefficients of the proportion of labor involved in the pruning, application of chemical and organic fertilizer, and labor investment are $0.079,0.404$, and 0.043 , respectively, and the interaction coefficients of the proportion of labor involved in flower/fruits thinning, application of chemical and organic fertilizer, and labor investment are $0.132,0.435$, and 0.044 , respectively. All the above factors are significant at the $1 \%$ and $5 \%$ confidence level, showing that with the increase of farmers' technical investment, the marginal output of the chemical fertilizer, organic fertilizer, and labor force investment will increase.

Notably, in addition, as the proportion of labor involved in pruning and flower/fruit thinning take values between 0 and 1 , with the introduction of logarithms of proportions of labor involved in various technical aspects, the real marginal output of chemical fertilizer and organic fertilizer became significantly negative. In other words, the traditional C-D production function model overestimates the marginal output of the chemical and organic fertilizers on fruit trees, and the impact on the marginal output of labor investment will need to be further calculated.

When the relevant production function coefficients from the estimation are substituted into the formula (11), we can acquire the mean value of the marginal output of the chemical fertilizers, organic fertilizers, and labor force of the total sample and of different age groups, as shown in Table 4 . For the total sample, the estimated marginal outputs of fertilizer use based on the investment into pruning and flower/fruit thinning are -0.155 and -0.286 , respectively, which are significantly lower values than the 0.490 estimated by the traditional C-D production function. The marginal outputs of the organic fertilizers (production function based on pruning: -0.794; production function based on flower/fruit thinning: -0.944) are also significantly lower than the traditional C-D production function estimates (0.101). Notably, the marginal outputs of the labor force based on the investment in the pruning and flower/fruit thinning are -0.084 and -0.095 , respectively; although these values are significantly 
negative at the confidence level of $5 \%$ and $10 \%$, they are significantly higher than the estimates from the traditional C-D production function. From the estimation results of the model, we find that the traditional C-D function or transcendental logarithm function really overestimate the actual marginal outputs and underestimate the marginal outputs of the chemical fertilizer, organic fertilizer, and labor force, meaning that their amounts have exceeded the best levels of usage.

Table 3. Estimates of production functions based on the different technical investments.

\begin{tabular}{|c|c|c|c|}
\hline Variable & $\begin{array}{l}\text { Traditional C-D Production } \\
\text { Function Estimate }\end{array}$ & $\begin{array}{l}\text { Production Function Estimate } \\
\text { Based on Investment in Pruning }\end{array}$ & $\begin{array}{l}\text { Production Function Estimate } \\
\text { Based on Investment in } \\
\text { Flower/Fruit Thinning }\end{array}$ \\
\hline $\operatorname{Ln}(N)$ & $\begin{array}{c}0.0758 \\
(0.93)\end{array}$ & $\begin{array}{l}0.2817^{* *} \\
(2.59)\end{array}$ & $\begin{array}{l}0.4423 \text { *** } \\
(5.61)\end{array}$ \\
\hline $\operatorname{Ln}(S)$ & $\begin{array}{l}-0.2260 * * \\
(-2.12)\end{array}$ & $\begin{array}{l}-0.2244^{* * *} \\
(-6.95)\end{array}$ & $\begin{array}{c}-0.1251^{* * *} \\
(-5.15)\end{array}$ \\
\hline $\operatorname{Ln}(O)$ & $\begin{array}{c}-0.0581 * \\
(-1.93)\end{array}$ & $\begin{array}{c}-0.1182 * * * \\
(-4.82)\end{array}$ & $\begin{array}{c}-0.0687^{* *} \\
(-2.51) \\
\end{array}$ \\
\hline $\operatorname{Ln}\left(F_{1}\right)$ & $\begin{array}{l}0.4901 * * * \\
(5.35)\end{array}$ & & \\
\hline $\operatorname{Ln}\left(F_{2}\right)$ & $\begin{array}{l}0.1005^{* * *} \\
\quad(2.92)\end{array}$ & & \\
\hline $\operatorname{Ln}(L)$ & $\begin{array}{l}-0.1253 \\
(-1.58)\end{array}$ & & \\
\hline $\operatorname{Ln}(H)$ & & $\begin{array}{l}0.6655 \\
(1.48)\end{array}$ & $\begin{array}{l}-0.2412 \\
(-0.67)\end{array}$ \\
\hline $\operatorname{Ln}(H)^{*} \operatorname{Ln}\left(F_{1}\right)$ & & $\begin{array}{c}0.0790 * \\
(1.70)\end{array}$ & $\begin{array}{c}0.1317^{* * *} \\
(3.03)\end{array}$ \\
\hline $\operatorname{Ln}(H)^{*} \operatorname{Ln}\left(F_{2}\right)$ & & $\begin{array}{l}0.4038^{* * *} \\
(4.12)\end{array}$ & $\begin{array}{c}0.4348^{* * *} \\
(4.88)\end{array}$ \\
\hline $\operatorname{Ln}(H)^{*} \operatorname{Ln}(L)$ & & $\begin{array}{l}0.0427^{* *} \\
(1.99)\end{array}$ & $\begin{array}{c}0.0436^{*} \\
(1.78)\end{array}$ \\
\hline _cons & $\begin{array}{l}8.8098^{* * *} \\
(12.18)\end{array}$ & $\begin{array}{l}8.7901 * * * \\
(9.77)\end{array}$ & $\begin{array}{l}7.9231 * * * \\
(12.00)\end{array}$ \\
\hline Prob $>F$ & 0.0000 & 0.0000 & 0.0000 \\
\hline$R^{2}$ & 0.4337 & 0.5758 & 0.5047 \\
\hline Obs & 256 & 256 & 256 \\
\hline
\end{tabular}

As for the different age groups, $t$ tests were carried out on the mean values of the young, the benchmark, and the elderly groups, and due to the different proportions of investment in the pruning and flower/fruit thinning, the mean value for the marginal outputs of the chemical fertilizers, pesticides, and labor for the elderly group are all significantly lower than those values for the benchmark group at the $1 \%$ and $5 \%$ confidence level, and these values showed the greatest difference in the marginal output of organic fertilizers. Specifically, the marginal outputs of the chemical fertilizers, organic fertilizers, and unit labor, as estimated by the production function with pruning considered, are $0.047,0.242$, and 0.026 units lower than those of the benchmark group, respectively. T marginal outputs of the chemical fertilizers, organic fertilizers, and unit labor, as estimated by the production function with pruning considered, are $0.047,0.242$, and 0.026 units lower than those of the benchmark group, respectively. Furthermore, the marginal outputs of the chemical fertilizers, organic fertilizers, and unit labor, as estimated by the production function with flower/fruit thinning considered, are $0.038,0.125$, and 0.016 units lower than those of the benchmark group, respectively, meaning the aging of the labor will have negative effect on the utilized rate of chemical fertilizer and organic fertilizer. 
Table 4. Analysis of marginal outputs of key production elements based on different technical investments.

\begin{tabular}{|c|c|c|c|c|c|c|}
\hline \multirow{2}{*}{$\begin{array}{l}\text { Production } \\
\text { Element }\end{array}$} & \multirow[t]{2}{*}{ Grouping } & \multirow{2}{*}{$\begin{array}{c}\text { C-D } \\
\text { Function } \\
\text { Mean }\end{array}$} & \multicolumn{2}{|c|}{$\begin{array}{l}\text { Function Based on } \\
\text { Pruning Investment }\end{array}$} & \multicolumn{2}{|c|}{$\begin{array}{l}\text { Function Based on Flower } \\
\text { Thinning Investment }\end{array}$} \\
\hline & & & Mean & Difference in Mean & Mean & Difference in Mean \\
\hline $\begin{array}{l}\text { Chemical } \\
\text { fertilizer }\end{array}$ & $\begin{array}{c}\text { Young } \\
\text { Old } \\
\text { Benchmark group } \\
\text { Total sample }\end{array}$ & 0.4901 & $\begin{array}{l}-0.1221 \\
-0.1887 \\
-0.1413 \\
-0.1553\end{array}$ & $\begin{array}{c}0.0192^{* *} \\
-0.0474^{* * *} \\
- \\
-\end{array}$ & $\begin{array}{l}-0.2964 \\
-0.2973 \\
-0.2595 \\
-0.2859\end{array}$ & $\begin{array}{c}-0.0369^{*} \\
-0.0377^{* *} \\
- \\
-\end{array}$ \\
\hline $\begin{array}{l}\text { Organic } \\
\text { fertilizer }\end{array}$ & $\begin{array}{c}\text { Young } \\
\text { Old } \\
\text { Benchmark group } \\
\text { Total sample }\end{array}$ & 0.1005 & $\begin{array}{l}-0.6241 \\
-0.9645 \\
-0.7222 \\
-0.7938\end{array}$ & $\begin{array}{c}0.0980^{* *} \\
-0.2423^{* * *} \\
- \\
-\end{array}$ & $\begin{array}{l}-0.9786 \\
-0.9814 \\
-0.8567 \\
-0.9441\end{array}$ & $\begin{array}{c}-0.1219^{*} \\
-0.1247^{* *} \\
- \\
-\end{array}$ \\
\hline Labor force & $\begin{array}{c}\text { Young } \\
\text { Old } \\
\text { Benchmark group } \\
\text { Total sample }\end{array}$ & -0.1253 & $\begin{array}{c}(2.92) \\
-0.1019 \\
-0.0764 \\
-0.0839\end{array}$ & $\begin{array}{c}0.0103^{* *} \\
-0.0256^{* * *} \\
- \\
-\end{array}$ & $\begin{array}{l}-0.0981 \\
-0.0984 \\
-0.0859 \\
-0.0947\end{array}$ & $\begin{array}{c}-0.0122 * \\
-0.0125^{* *} \\
- \\
-\end{array}$ \\
\hline
\end{tabular}

Note: ${ }^{*} p<0.1,{ }^{* *} p<0.05,{ }^{* * *} p<0.01$, the standard deviation shown in parentheses is robust standard error.

\section{Conclusions and Policy Implications}

Based on the field research data and the crop cultivation characteristics of Jiangsu Province, this paper introduces technical investments into the traditional C-D production function and calculates and analyzes the impact of the aging labor force on the output of fertilizers on peach trees and other crops that show a weak potential for mechanization. Through empirical research, this paper mainly draws the following conclusions:

First, for peach trees, which need pruning and thinning of flowers (fruits), effectively adjusting the relation between the peach tree growth and fruit development is possible by relying on artificial pruning and thinning to avoid excessive tree growth and increase the unit production value of the chemical and organic fertilizers.

Therefore, if the traditional C-D production function is used to estimate the marginal output of chemical and organic fertilizers while neglecting the investment of pruning and thinning techniques, the marginal output of production elements will be overestimated, whereas that of the labor force will be underestimated and thus cannot provide effective judgments on the application of factors like fertilizers. It is very necessary to consider the investment of pruning and thinning techniques into production function of fruit, such as peach, pear, and apple.

Second, with the progressive aging of the labor force, although old farmers have more time to engage in the cultivation and management of peach trees, due to the different labor demands of the various production processes, the increased labor is not proportionally distributed among the processes. In labor-intensive, technical aspects such as pruning and thinning of the flower/fruit, the proportion of labor investment from the older farmers is obviously lower than that of the benchmark group. In further analyzing the marginal outputs of key production elements, the investment in the pruning and flower/fruit thinning has a significant positive effect on the marginal output of chemical and organic fertilizers. Foreseeably, for peach, apple, and other fruit trees that require pruning and flower/fruit thinning, with the aging of the labor force, the elderly farmers will experience a continued decline in their investment in pruning and flower/fruit thinning, thereby reducing the application efficiency of chemical and organic fertilizer and resulting in uneconomical investment in fertilizers.

For a long time, the production and output value of apples, pears, peaches, etc. have been at the forefront of China's fruit industry. Under the background of the aging of the agricultural labor force in China, a full understanding of the possible negative impact of an aging labor force on crop production and study of the possible impact of this aging labor force on fruit cultivation, which requires high labor intensity and has a weak potential to be mechanized, are necessary to actively take measures to respond to the challenge. First, an emphasis and increase in research, development, and the promotion 
of relevant technologies is needed. On the one hand, innovation should be actively promoted and new pruning shapes for the fruit trees should be explored to improve the convenience of follow-up pruning actions; on the other hand, improvements are needed in the existing tools for pruning and flower thinning, and more electric pruning tools should be developed. Second, operation scales should be expanded through land transactions or cooperatives to increase the proportion of machinery use in pesticide application and other processes that show a good potential for mechanization, with improvements in agricultural product branding being gradually established, and to achieve high quality and good prices through branding and large-scale production, thus ensuring labor force engagement. Moreover, we can pilot the outsourcing of relevant technical aspects and make up for the disadvantage of old farmers in technical investment through the formation of regional professional technical service organizations.

Acknowledgments: This article was sponsored by the National Modern Agricultural Industry Technical System Construction Special Funds (CARS-30), The National Natural Science Foundation of China (71603129), The Priority Academic Program Development of Jiangsu Higher Education Institutions (PAPD), the Jiangsu Province Graduate Research Fund, and China Center for food Security Studies, Nanjing Agricultural University.

Author Contributions: Bin Yuan, Jintao Zhan, and Chao Chen conceived and designed the experiments; Bin Yuan and Jintao Zhan performed the experiments; Bin Yuan analyzed the data; Jintao Zhan contributed analysis tools; Bin Yuan wrote the paper; Chao Chen revised the paper.

Conflicts of Interest: The authors declare no conflict of interest.

\section{References}

1. Liu, H.; Zhang, W. The significance and technical essentials of pruning fruit trees. China Hortic. Abs. 2014, 8, 207-208.

2. Wang, X.F.; Meng, Y.P.; Cao, Q.F. Advances in apple chemistry and fruit thinning. J. Fruit Sci. 2006, 2, 437-441.

3. Wang, Z.; Song, Y.Z.; Liu, H. China's fruit tree pruning machinery research status and development trends. J. Agric. Mech. 2017, 3, 126-130.

4. Feng, X.Y. High-yield high-quality peach cultivation. Liaoning Sci. Tech. Press. 2010, 9, 56-62.

5. Zhong, F.N.; Wang, Y.N. Study on the inner growth level of Chinese population from a queue perspective: A comparison of two kinds of estimation methods based on lifetime fertility rat. Popul. Econ. 2015, 2, 1-10.

6. Kathrin, H.; Hans, W.O.; Onno, O.; Stefanie, B. Drivers for the Adoption of Different Eco-Innovation Types in the Fertilizer Sector: A Review. Sustainability 2017, 9, 2216.

7. Bahar, C.E.; Ebru, G.S. In the Presence of Climate Change, the Use of Fertilizers and the Effect of Income on Agricultural Emissions. Sustainability 2017, 11, 1989.

8. Mai, B.J.; Xi, H.W.; Yun, H.; Liu, S.; Xue, Q.S.; Cheng, Y.Z.; Hua, L. Diversity and Abundance of Soil Animals as Influenced by Long-Term Fertilization in Grey Desert Soil, China. Sustainability 2015, 8, 10837-10853.

9. Li, M.; Zhao, L. On the aging of the agricultural labor force and its impact on agricultural production-Based on an empirical analysis of Liaoning Province. Agric. Econ. 2009, 10, 12-18.

10. Yuan, B.; Chen, C. Elastic relationship between rural labor force migration and fruit production. J. South China Agric. Univ. 2016, 4, 42-51.

11. Xu, N.; Zhang, L.Q. Effect of aging labor force on agricultural production efficiency in China. J. China Agric. Univ. 2014, 4, 227-233.

12. Hu, X.Z.; Zhong, F.N. Impact of an aging rural population on grain production-Based on the analysis of fixed observation point data. China Rural Econ. 2012, 7, 25-36.

13. Lin, B.X.; Deng, H.S. An empirical analysis of the impact of aging rural labor on land utilization efficiency, based on an analysis of fixed observation point data in rural Zhejiang Province. China Rural Econ. 2012, 4, $15-25$.

14. Ji, Y.Q.; Wang, Y.N.; Zhong, F.N. Study of the Farmers' Agricultural Machinery Demand and Its structure in China, based on the provincial level data. J. Agro Tech. Econ. 2013, 7, 19-26.

15. Koenker, R.; Bassett, G. Regression quintiles. Econometric 1978, 3, 107-112. 
16. Shao, H.L.; Wen, J.J.; Qing, W.M.; Jian, Z.Y. The Influences of Production Factors with Profit on Agricultural Heritage Systems: A Case Study of the Rice-Fish System. Sustainability 2017, 10, 1842.

17. Angelos, L.; Irene, T. Economic Sustainability of Organic Aloe Vera Farming in Greece under Risk and Uncertainty. Sustainability 2016, 4, 338.

18. Shen, Y.; Shao, B.P. Exploring the Trends in Nitrogen Input and Nitrogen Use Efficiency for Agricultural Sustainability. Sustainability 2017, 10, 1095. [CrossRef]

19. Egger, H.; Egger, P. Interactional outsourcing and the productivity of low-skilled labor in the EU. Econ. Inq. 2006, 1, 98-108. [CrossRef]

20. Wang, J.; Huo, X.X. Analysis of the joint selection behavior and influencing factors of orchard fine management technology, using apple growers in Luochuan, Shaanxi as a case study. J. Nanjing Agric. Univ. $2012,2,58-68$.

21. Gai, Q.E.; Zhu, X.; Shi, Q.H. The impact of labor migration on China's agricultural production. Econ. Q. 2014, 3, 1147-1170.

(C) 2017 by the authors. Licensee MDPI, Basel, Switzerland. This article is an open access article distributed under the terms and conditions of the Creative Commons Attribution (CC BY) license (http:/ / creativecommons.org/licenses/by/4.0/). 